THURSDAY, APRIL 25,1878

\section{THE COMING TOTAL SOLAR ECLIPSE ${ }^{-}$}

II.

$\mathrm{N}$ my former article I referred to the possible employment of slitless spectroscopes during the coming eclipse, the prism being replaced by a grating in some cases. It will be convenient here to give the results arrired at by the Siam Expedition with an instrument of this description, which, for shortness, was called a prismatic camera.

The plates secured present at first sight a very puzzling appearance; they are unlike anything ever obtained before, and a good deal of thought had to be spent upon them before all the knowledge they were afterwards found capable of furnishing to us was properly appreciated. Cne of the plates was exposed for one minute at the commencement of totality, the other for two minutes at the end. The differences between them are those due to the phases of the eclipse. In the first, two strong protuberances close together are photographed; these are partially covered up in the second, while another series is revealed on the following limb in consequence of the motion of the moon over the sun.

Now in both the photographs-that exposed for one minute and that exposed for two-the strongest of the prominences are repeated three times, that is to say, three spectral images of them are visible, each of these images being produced by light of different wave-lengths which the prominences emitted.

The question is what are these particular wave-lengths thus rendered visible? Unfortunately no photograph was taken of the cusps either before or after totality; a scale therefore was cut of the question; and when the task of assigning ware-lengths to these spectral images fell upon Dr. Schuster and myself, while we were preparing the Report which was sent in to the Royal Society last year, the difficulties we encountered were very considerable.

Everybody I think will consider that we were justified in expecting the lines of hydrogen to be represented in such a photograph. Now the photographic hydrogen lines are those at $F$, near $G$ and at $h$, and the silver salts usually employed are such that the action is most intense near $\mathrm{G}$, less intense near $h$, and least at $\mathrm{F}$; the running down from $G$ to $F$ being rapid, and that from $G$ to $h$ much more gradual, so that while at one end $F$ may be said to be the limit of photographic activity, at the other it is continued long past $h$. We were therefore justified in assuming as the preliminary hypothesis, that the image of least refrangibility was produced by the $F$ light of hydrogen, the more so as the continuous spectrum also photographed-which continuous spectrum, as we had independent means of determining, came from the base of the corona-gave us also an idea of the part of the spectrum in which each image was located.

Talsing then $F$ as a starting point and assuming the next line to be the one near $G$, we had a quite satisfactory method of checking the assumption, by comparing the real distance between the images with the calculated one.

\footnotetext{
I Continued from p. $4^{8} 3$.
}

A goniometer was therefore brought into requisition, and the angular distance between $F$ and the line near $G$ carefully measured in order to determine the dispersion of the prism actually employed. This dispersion was one which should bring the images about as far apart as they were actually found to be; this therefore was so far in favour of our assumption, that is to say, it did look as if we had got hold, on the photographs, of images of the prominences built up by the $F$ and $G$ light of hydrogen.

It was next the turn of the third line, the one at $h$. On the assumption already made, it was easy to determine the distance from the $G$ image, at which the one representing $h$ should lie. In this place, bowever, we found no image whatever of any of the prominences.

Now this was a very extraordinary result, and there was only one way, so far as we could then see, of accounting for it. Dr. Frankland and myself, nearly ten years ago now, produced evidence which seemed to indicate that this line of hydrogen was only produced by a very high temperature. This being so, then, we should have to conclude that the prominences were of a relatively low temperature; this, however, I am far from saying, and bere there is undoubted work of the greatest value to be done at the next eclipse, and I for one feel certain that our American cousins will do it.

I have not, however, yet referred to the strongest image of all shown in the photographs. This lies a little further from the centra! one than does the first on the other side of it. $\mathrm{Cn}$ the assumption before stated its wave-length lies somewhere near 3957. This number, of course, is only an approximate one, but the region occupied by the line was obviously so near the boundary of the visible spectrum, that a long series of experiments, in which we called in the aid of photogaphy and fluorescence, was made in order to determine whetber an unrecorded hydrogen line existed in that region. All I can say is that the point may be said to be yet undetermined. It is quite true that in several vacuum tubes which Dr. Schuster and myself employed, a strong line more refrangible than $H$ was seen, but then these same tubes unfortunately showed us lines in the visible spectrum, which beyond all doubt did not belong to hydrogen. The elimination of impurities is such a delicate matter, and one requiring such a large expenditure of time, that our report was sent in leaving this point sub judice. We tried hydrogen at atmospheric pressure in order to get such a predominance of the hydrogen vibrations as to mask the impurities, but this did not serve us, for the continuous spectrum was so bright in the violet and ultra-violet as to render observations of lines next to impossible. Cwing to many reasons, Dr. Schuster's absence from London being one of them, we have not been able to renew the search.

The near coincidence of this spectral image with the $\mathrm{H}$-line leads us to ask the question whether Young's beautiful work in his mountain observatory might not help us on this point. Young found the calcium lines always reversed in the penumbra and near every large spot. This important statement shows us that calcium is one of the metallic vapours which is most frequently ejected from below into the prominences; it is possible, therefore, that the prominences, the spectral images of which were photographed, may have been due 
to an eruption of calcium. This, of course, is only a suggestion, but the fact that it is a suggestion merely shows how important it is that this point should engage attention next July. If the prominences are then constituted as they were in '75, this violet line will cloubtless turn up again, and that is why I have been most anxious to point out not only the conclusions to which we have been led, but the extreme difficulty of arriving at any conclusion whatever, unless by one method or another we have an absolute comparison of the spectrum of the prominences with that of the sun itself.

I have before referred to the fact of the registration on the plates of a continuous spectrum. If we were to suppose the whole light of the corona to be due to 1474 light, for instance, we should expect to get just as definite an image of the corona in the prismatic camera as in an ordinary one. And if everything outside the moon gave us nothing but a line spectrum, the moon's limb would have a perfectly defined edge. Now as a matter of fact, only one such edge is seen in the photographs. We have only one complete ring with a thoroughly defined hard outline, such as that to which reference has been made. This hard ring corresponds to the second spectral image of the prominences, and is a continuation of it. Supposing we were right about the prominences, the ring would be due to the high temperature $h$ line of hydrogen (supposing us wrong it might be a companion line to 1474 ); as the observations of Respighi, Janssen, and others, in the Indian eclipse of ' $7 \mathrm{I}$ endorsed the American observations of ' 69 that the hydrogen lines are the strongest in the photographic parts of the corona, we may very possibly be really dealing with hydrogen.

Now the edge of the corona, or the upper part of it considering it as the sun's atmosphere, as seen on our photographs, is precisely such as would be given by homogeneous light; that is, there is a distinct image, and there is one image and not three or any other number. Have we any means of determining the wave-length of the light by which this image has been produced? Let me give an idea of one method which we employed:-A circle of the same size as the image of the moon on a photographic enlargement of the original negative was cut in paper and placed over the enlargement until the corona was symmetrical round it, as we know it to have been symmetrical round the moon's body, or nearly so, at that phase of the eclipse.

We found as a considerable endorsement of the assumption which we made regarding the hydrogenic origin of the chromospheric images, that the paper circle in this position had its circumference coincident with the hard ring to which $I$ have referred as being a continuation of the middle spectral image of the prominences. Next, one of the ordinary photographs of the corona was enlarged to the same size as that of the one produced in the prismatic camera. When these were superposed so that the outlines of both coincided as much as possible, it was again found that the edge of the moon lay along the ring.

Now then for the continuous spectrum. The general woolliness of the photographs which at first sight gives rise to the idea that they were out of focus, and that there is nothing to be got out of them, is of course only in one direction, that at right angles to the edge of the prism employed. There is a well-defined structure running parallel to this direction, which of course is the line of dispersion; this structure is doubtless due to irregularities in the corona, drawn out by the prism into bands; it is easy to determine the limits of this continuous spectrum.

Examining the centre of the photographs we find that on one side the structure stops short at F, on the other it extends to a considerable distance beyond the prominence image in the ultra-violet, spaces of light being visible beyond 3530 .

From these data we concluded that the continuous spectrum-giving region extends at least to a distance of $3^{\prime}$ of arc from the sun's limb. This continuous spectrum is well shown on photographs taken at the beginning and end of the eclipse. One of the plates of the prismatic camera was exposed, until the signal for the end of totality was given. Dr. Schuster states that all the observers agreed that the signal was given rather too late, and the fog on the plate indicates an intense illumination ; nevertheless, the edge of the sun is not drawn out into a continuous band but rather into three distinct bands. It is probable, therefore, that when the plate was exposed, only the lower part of the chromosphere had appeared, and that it gave out light of such intensity that everybody imagined that the sun itself had come out of eclipse. I observed this myself in 1871 , and a very striking fact it is.

So much then for the results obtained by the prisuatic camera in '75. When the report is issued-and its issue cannot be much longer delayed-it will be seen that the hasty sketch I have now given can be followed in greater detail.

One of the most remarkable points about the expeclition to Siam was the failure to obtain even spectra of the sun with the ordinary telespectroscopic cameras employed. No doubt the unforeseen delays which left very little time for the adjustment of instruments, have a great deal to answer for. I have little cloubt that if the attempt is made next July, when any quantity of skilled help will be at hand, and any amount of rehearsal will be possible, that a full measure of success will be obtained, at all events for the most photographic part of the spectrum. An ordinary photograph of the corona was obtained by Dr. Schuster in two seconds; and my experience with photographic spectra enables me to say that this photograph was taken by means of an almost monochromatic light--that near G. Now as the coming eclipse will enable an exposure of almost 100 times longer than this to be employed, I do not think that the undoubted feebleness of the object need be feared. Besides, this method would enable us to pick up the light of those lower reaches of the chromosphere which, as has been already stated, are of such extreme brilliancy as to have been mistaken, on many occasions, for the sun itself.

Up to the present time no attempt has been made to obtain a photographic record of the polarisation of the corona. The difference of colours indicating radial polarisation observed by me when I used the biquartz in $187 \mathrm{r}$, certainly have left the impression on my mind that it would be quite easy to obtain a permanent record of them. This would be a very valuable result, and one 
which would set at rest a question which, though I consider it settled in my own mind, is yet, I believe, held to be still doubtful by many interested in these matters.

In what I have written I have touched only upon obvious work suggested by the previous observations. I have little doubt that the preparations of the skilled astronomers of the United States include many surprises and claring attempts among the solid work which we are quite certain of.

All here wish them the extremest measure of success, which I am sure their efforts will do more than command.

\section{J. NORMAN LOCKYER}

\section{ATLANTIC SHELLS}

Testacea Atlantica; or, the Land and Freshwater Shells of the Azores, Matciras, Salvages, Canaries, Cape Verdes, and Saint Helena. By T. Vernon Wollaston, M.A., F.L.S. Royal Svo, pp. 588. (London: L. Reeve and Co., 1878.)

$T^{T}$ is with a saddened feeling we take up our pen to notice this valuable contribution to malacology; for ere its pages had left the hands of the binder, its talented author had passed "into the shadowy land."

The name of Wollaston is connected ancestrally with more than one department of science, and the author of the present work has well maintained the honourable reputation of $\mathrm{Dr}$. Wollaston, the discoverer of palladium and rhodium, and the founder of the Wollaston Medal and $A$ wart.

Compelled in $18_{47}$ to visit Madeira on account of his health, he commenced to collect the landshells of the various outlying islands and rocks of the Madciran Group; and although (as he tells us) insects, rather than mollusca, formed at that time the main object of his rescarches, he was able to add a considerable number of unmistakably new species to the careful and elaborate catalogue which had previously been compiled by his friend and companion, the late Rev. R. T. Lowe, then chaplain at Funchal, Madeira, and to whom the present work is dedicated.

So interested did he become in the insects and land snails of Madeira, that, although no longer compelled to submit to exile on account of his health, yet he returned again and again to Madeira and spent many weeks under canvas high up among the mountains collecting.

In 1858 he visited the Canaries in the yacht of his friend, Mr. John Gray, and again in 1859. On both these expeditions he was accompanied by Mr. Lowe. He was thus cnabled thoroughly to explore the numerous and widely-scattered islands of the Canarian group under the most fortunate circumstances for collecting.

Under the same happy auspices he visited the Cape Verdes in 1866, Mr. Lowe again being his companion. In 1875 Mr. Wollaston sailed for St. Helena with Mr. Gray, where he spent six months in investigating the natural history of that remote little oceanic rock, being on this occasion accompanied by Mrs. Wollaston; the Rev. R. T. Lowe, his friend of many past years, having lost his life in 1874 on his outward voyage to Madeira.

Mr. Wollaston has felt it desirable to place these facts on record, in order to show that the several islands and archipelagos treated of in the volume before us - with the exception of the Azores-had all been visited personally by himself.

Although this book contains descriptions of no fewer than 558 species and varieties of land and freshwater mollusca, the author does not claim for it the position of a monograph, but rather a critical enumeration of all the forms hitherto recorded, with special reference to habitat in the several Atlantic archipelagos.

Out of the large number of species and varieties described in this work, there are only twenty-nine which are claimed by the author as actual novelties; sixteen of these are from the Canaries, nine from Madeira, two from St. Helena, one from the Salvages, and one from the Cape Verdes. Mr. Wollaston would have conferred a still greater service on his fellow-workers had he given short diagnostic characters of all the species enumerated. This would greatly have facilitated the identification of the various forms and saved the student much time and avoided the necessity of referring in many instances to other works. It is also much to be regretted that references are not given to the excellent published figures of most of the species which are to be found in Reeve's "Conchologia Iconica" and the second edition of Martini and Chemnitz's "Conchylien Cabinet" by Küster. Well-drawn and correctly-coloured figures are almost indispensable for the accurate determination of land-shells where form and colour are dominant characters. It is easy to see and identify the form, when carefully delineated, but almost an impossibility to convey it to the mind in words.

Mr. Wollaston has shown throughout the strongest preference for the limitation of species-at times becoming extremely hypercritical-and in some instances he seems to be altogether in doubt as to what constitutes specific rank. For example, under Helix bicarinata (vide p. 16I), he states that he is far from certain that it is more than a phasis of $H$. cchinulata; yet a few lines below he observes that he has never found a single example among thousands which could be strictly regarded as intermediate.

Again (p. 209) Pupa fanalensis, " this may be only a depauperated state of the var. $\beta$. anconostoma of the Pupa umbilicata, which the latter has gradually assumed through having found its way into the higher regions, nevertheless I believe it to be truly distinct."

It is strange to find a man with Wollaston's admitted talents and vast opportunities for observation struggling hard against the accumulated evidence of more than thirty years, and clinging tenaciously to the last to the doctrine of the immutability of species. Thus in his Summary (p. 56I), when commenting on the difficulties which arise in defining what is a "species" and what a "variety," he adds, "these remarks are by no.means intended to insinuate that the lines of demarcation between species, when correctly interpreted, are ever, in my opinion, really confused or doubtful, the exact opposite having" always been my firm belief."

Eliminating what Wollaston calls "the European or more distinctly Mediterranean forms" from the catalogue, so that only "the Atlantic element" remains, "the actual species which range beyond the limits of a single archipelago are marvellously few-about four or five being common to the Madeiras and Azores, about 